\title{
Perancangan Alat Pengukur Detak Jantung Menggunakan Pulse Sensor Berbasis Raspberry
}

\author{
Putri Karina ${ }^{1}$, Ahmad Hamim Thohari ${ }^{2}$ \\ Teknik Informatika, Politeknik Negeri Batam \\ putrikarin316@gmail.com ${ }^{1}$, hamim@.polibatam.ac.id ${ }^{2}$
}

\begin{tabular}{|c|c|}
\hline Article Info & ABSTRACT \\
\hline Article history: & Health is a prosperous state of body, soul, and social that enables everyone to live \\
\hline $\begin{array}{l}\text { Received : 26-09-2018 } \\
\text { Revised : 29-11-2018 } \\
\text { Accepted : 05-11-2018 }\end{array}$ & $\begin{array}{l}\text { socially and economically productive. The heart is a vital organ in the body that } \\
\text { affects health, heartbeat is one of the parameters that paramedics use to know health. } \\
\text { Stethoscope is a common tool used in measuring heart rate, simple and easy to carry, } \\
\text { but has a deficiency in its use directly by experts / medical who have knowledge of }\end{array}$ \\
\hline Keyword: & $\begin{array}{l}\text { Stethoscope in achieving accurate results in accuracy requires concentration in } \\
\text { finding results and Stethoscope itself can not be used by ordinary people who do not }\end{array}$ \\
\hline $\begin{array}{l}\text { Kesehatan, } \\
\text { Raspberry, } \\
\text { Sensor Pulse, } \\
\text { Monitoring. }\end{array}$ & $\begin{array}{l}\text { understand. Pulse and Raspberry sensor control using MCP } 3008 \text { that serves as an } \\
\text { analog to digital converter. Thus, it is hoped to detect the heart rate increase with } \\
\text { ease accurately and the measurement can be done by itself. This final project } \\
\text { proposes the design of heart rate measurers in a fast and accurate way in a relatively } \\
\text { accurate calculation of results. The workings of this tool is to retrieve data from the } \\
\text { pulse sensor detection for heartbeat and then displayed on the monitor screen. }\end{array}$ \\
\hline
\end{tabular}

Copyright (C) 2018 Journal of Applied Informatics and Computing. All rights reserved.

\section{Pendahuluan}

Kesehatan merupakan harta yang tak ternilai bagi seseorang, sehingga seseorang rela melakukan segala cara agar dapat menjaga kesehatan. Siapa saja dapat mengalami gangguan kesehatan tanpa mengenal usia, jenis kelamin, pekerjaan. Berdasarkan The World Health Report, 2005 angka kematian seseorang akibat diagnosa kesehatan yang lambat serta penanganan yang buruk oleh tim medis di Indonesia pada mencapai $8-11 / 100.000$ populasi manusia hidup, hal ini merupakan angka yang termasuk tinggi di ASEAN. Penyakit jantung adalah salah satunya penyakit yang sangat berbahaya. Pada tahun 2014 di Asia Tenggara Khususnya di Indonesia, angka kematian 35\% atau 1.8 juta kasus kematian terbanyak akibat penyakit jantung dimana penyakit tersebut adalah penyakit yang lambat dalam penanganan. Detak jantung merupakan paremeter yang penting untuk mengetahui kondisi fisik maupun mental seseorang. merupakan salah satu penyakit yang serius dan mengakibatkan kematian tertinggi di dunia. Penyakit yang berada didalam tubuh manusia yang membutuhkan waktu dan kondisi yang tepat untuk melakukan pengecekan dirumah sakit, peningkatan kolesterol, darah tinggi, diabetes dan faktor lainnya yang diiringi dengan peningkatan detak jantung. Stetoskop merupakan salah satu alat yang biasa digunakan di medis untuk mengukur detak jantung, alat yang mudah dan sederhana dalam penggunaanya, Tetapi memiliki kekurangan yang sangat mendasar dalam segi fungsionalnya. Kekurangan itu, antara lain : membutuhkan waktu yang relatif cukup lama dan berulang - ulang dalam mendapat hasil yang tepat dan akurat karena membutuhkan konsentrasi dalam menghitung detak jantung dan keakuratan yang tepat untuk mengetahu hasilnya.

Dengan aktifitas seseorang yang sangat komplek, penyakit yang menggagu secara tiba - tiba dimungkinkan dapat terjadi, dan aktifitas atletik olahraga yang memerlukan monitoring kondisi tubuh agar nantinya tidak menggangu pelatihan yang dilakukan dan seseorang yang memiliki masalah bawaan pada kondisi tubuh seperti, cacat jantung bawaan, lemah jantung dan infeksi jantung.

Salah satu metode dalam pengukuran detak jantung menggunakan sensor pulse. pulse sensor itu sendiri dimana cara kerja dari sensor yang dapat mendeteksi pergerakan detak jantung di dalam tubuh seseorang dengan memanfaatkan peedaran darah disetiap menit dengan saraf arteri yang menjadi fokus dalam penghitungan volume dan 
dapat mendeteksi kondisi kesehatan, sehingga dapat mendorong untuk menjaga kesehatan tubuh serta dapat mengontrol dan mendeteksi kondisi seseorang.

\section{LANDASAN TEORI}

Cara termudah untuk mengikuti aturan format halaman JAIC adalah menggunakan format dalam dokumen ini. Simpanlah file ini dengan nama lainnya, lalu ketikkan isi makalah anda ke dalamnya.

\section{A. Jantung}

Jantung adalah organ yang berupa otot, berbentuk kerucut, berongga, dengan pangkal diatas dan puncaknya dibawah miring kesebelah kiri. Jantung terletak di dalam rongga dada diantara kedua paru-paru, dibelakang tulang dada, dan lebih menghadap ke kiri daripada ke kanan. Jantung berfungsi untuk memompa darah keseluruh tubuh melalui pembuluh darah.(Perace, 200:125). Jantung memiliki empat ruangan yaitu, dua ruangan atas (atrium) dan dua ruangan bawah (ventrikel).

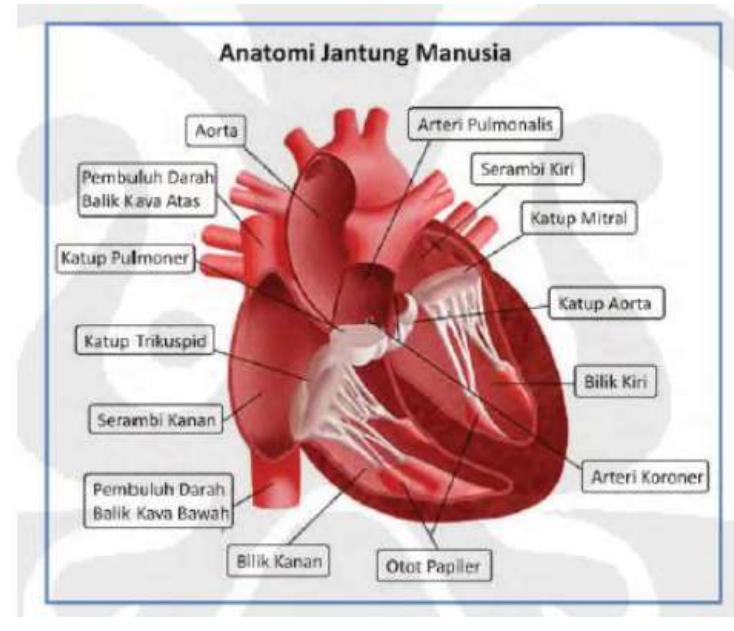

Gambar 1.Anatomi Jantung

TABEL I

DETAK JANTUNG PER MENIT BERDASARKAN UMUR

\begin{tabular}{ll}
\hline Umur & $\begin{array}{l}\text { Jumlah detak per } \\
\text { menit }\end{array}$ \\
\hline $\begin{array}{l}\text { Bayi baru lahir } \\
\text { Anak usia 1-10 }\end{array}$ & $\begin{array}{l}120-160 \\
\text { tahun }\end{array}$ \\
$\begin{array}{l}\text { Anak usia }>10 \\
\text { dan Dewasa }\end{array}$ & $60-80$ \\
\hline
\end{tabular}

Denyut nadi normal: 60 - 100/menit

Denyut nadi maksimal: 220/menit atau untuk mengetahui beat per menit (bpm) dapat diketahui dengan menggunkan rumus BPM yaitu :

$$
B P M=\frac{60}{\text { waktuperhitungan }} x j u m l a h d e t a k
$$

\section{B. Jaringan Sensor Nirkabel}

Jaringan sensor nirkabel merupakan suatu jejaring nirkabel menggunakan alat berupa sensor yang bekerjasama untuk memantau kondisi tertentu seperti temperatur, suara, cahaya, tekanan dan lainlain. Jaringan sensor nirkabel merupakan suatu jaringan sensor yang terdiri dari node sensor yang disebar pada beberapa titik, dan dapat melakukan komunikasi tanpa kabel. Jadi konsep sederhana dari suatu jaringan sensor nirkabel adalah berdasarkan fungsi pengindraan, CPU dan Radio.

\section{Raspberry Pi}

Komputer papan tunggal (Single board circiut/SBC) yang memilki ukuran sebesar kartu kredit, Raspberry Pi memiliki dua model yaitu model A dan model B. Secara umum perbedaan model terletak pada memory yang digunakan, Model A menggunakan memory $256 \mathrm{MB}$ dan B $512 \mathrm{MB}$. Raspberry Pi bersifat Open Source (berbasis Linux), Raspberry Pi bisa dimodifikasi sesuai kebutuhan penggunanya. Sistem Operasi utama Raspberry Pi menggunakan Debian GNU/Linux dan bahasa pemrograman Python. Salah satu pengembang OS untuk Raspberry Pi telah meluncurkan Sistem Operasi yang dinamai Raspbian, Raspbian diklaim mampu memaksimalkan perangkat Raspberry Pi. Sistem operasi tersebut dibuat berbasis Debian yang merupakan salah satu distribusi Linux OS.

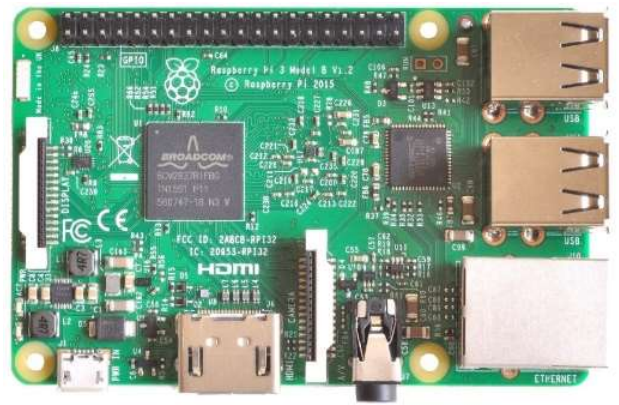

Gambar 2.Raspberry Pi 3 model B+

\section{Sensor}

Alat untuk mendeteksi/mengukur sesuatu, yang digunakan untuk megubah variasi makanis, magnetis, panas, sinar dan kimia menjadi tegangan dan arus listrik. Dalam lingkungan sistem pengendalian dan robotika, sensor memberikan kesamaan yang menyerupai mata, pendegaran, hidung, lidah yang kemudian akan diolah oleh kotroler sebagai otaknya.

\section{E. Pulse Sensor}

Pulse sensor adalah sensor yang dapat menghitung denyut jantung manusia yang diproduksi oleh fungky corporation. 


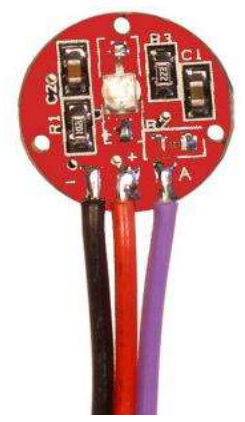

Gambar 3.Pulse Sensor

Sensor ini menggunakan infrared dan photodiode. Infrared akan memancarkan sinyal yang menembus kulit pada tangan yang kemudian akan ditangkap oleh photodiode. Konsepnya adalah infrared dan photodiode akan menangkap perubahan volume darah pada jari tangan pada saat jantung memompa darah keseluruh tubuh.dari sinilah data denyut jantung akan didapatkan untuk kemudian diproses.

\section{METODOLOGI PENELITIAN}

Metode penelitian yang digunakan adalah eksperimen yaitu dengan merancang, membuat, menguji, dan mengimplementasikannya pada rangkaian yang telah terintegrasi secara otomatis.

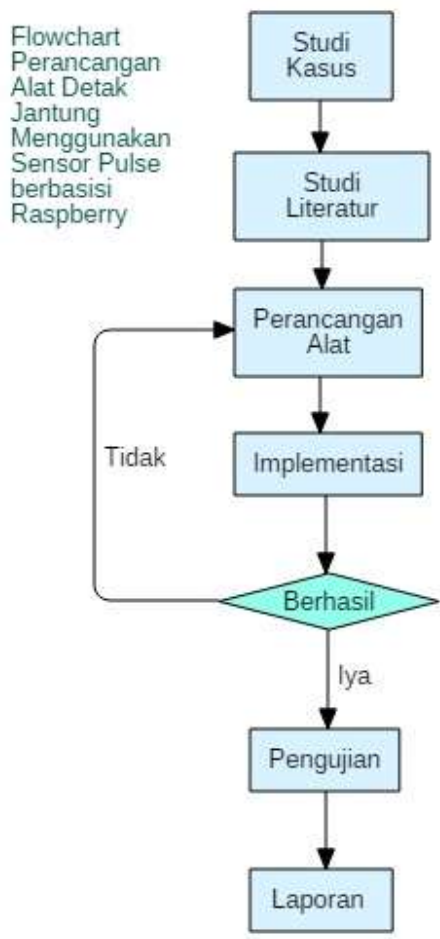

Gambar 4. Flowchart Metode Penelitiaan.

\section{ANALISI DAN PERANCANGAN}

Sensor Pulse yang bertujuan menampilkan informasi dari BPM dari pengukuran yang mendeteksi detak jantung pada aliran darah pada jari tangan. Adapun rancangan penelitian ini terdiri dari Perancangan hardware dan Integrasi software serta penelitian yang digunakan dalam pengukuran dan pengujian terhadap alat yang dibuat.

\section{A. Gambaran Sistem}

Sistem pengukuran detak jantung menggunakan Raspberry Pi sebagai proses utama dan pengolahan. Sensor pulse sebagai pembaca inputan yang memberikan masukan singnal Analog kemudian diteruskan ke Raspberry P $i$ dengan bantuan MCP 3008 dalam mengubah singnal analog ke digital agar dapat terbaca oleh Raspberry.

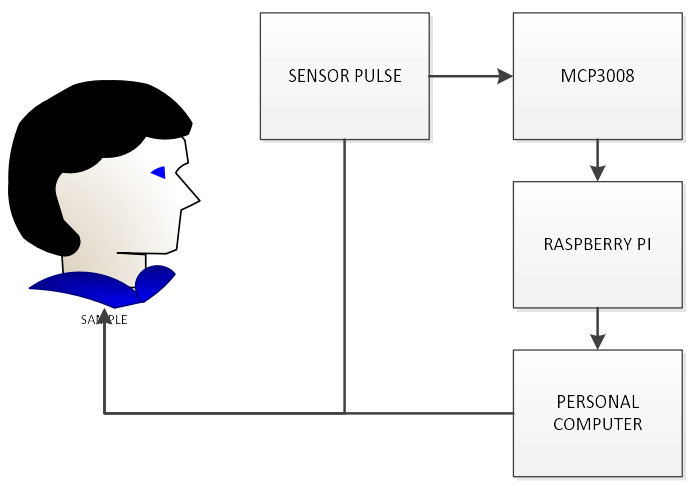

Gambar 5.Diagram Sistem

\section{B. Diagram Blok Sistem}

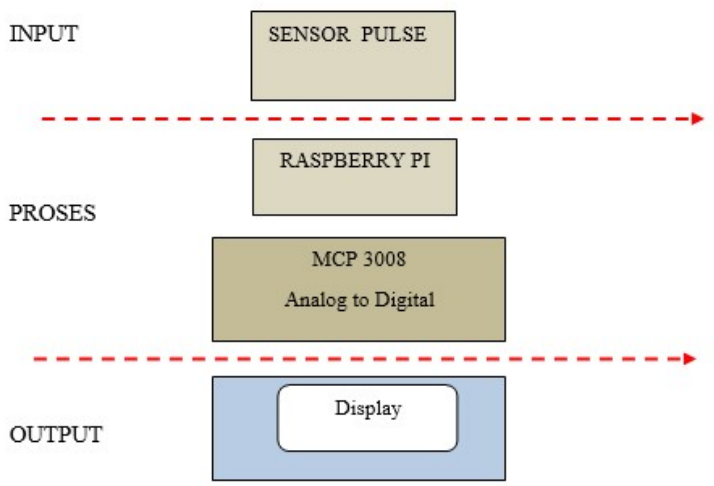

Gambar 6. Contoh di atas adalah contoh grafik garis menggunakan warna yang berbeda yang dapat memberikan kontras yang baik di layar maupun di proceeding cetakan.

\section{Teknik Pengolahan dan Analisi Data}

Dalam metode tersebut dapat memiliki kuantitatif yaitu menjamin validitas dan realibilitas data dari pengujian yang dilakukan. Memanfaatkan peralatan microcontroller yang mendukung adanya keakuratan penghitungan serta validasi yang tersimpan di dalam memori penyimpanan. 


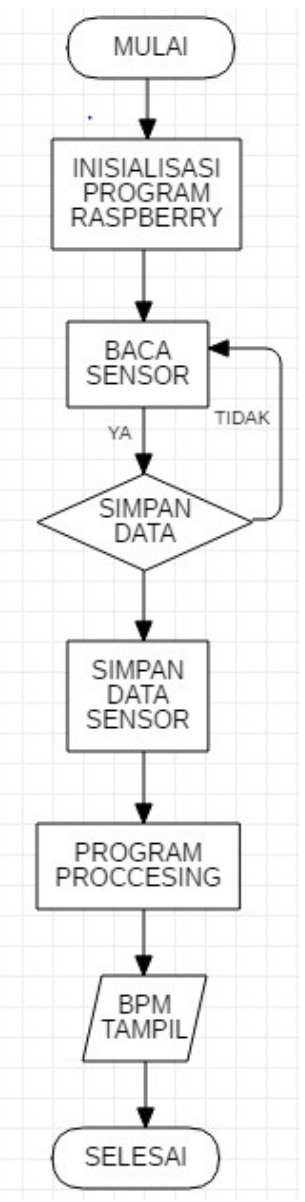

Gambar 7.Flowchart Proses Raspberry

\section{Perancangan Rangkaian Alat}

Pada perancangan sensor detak jantung dibutuhkan sensor yang mampu mendeteksi detak jantung melalui peredaran darah dengan memanfaatkan sensor cahaya dam optik, sensor yang digunakan adalah pulse sensor atau heart rate monitoring. Sensor ini diletakkan pada ujung jari yang akan menghasilkan denyut jantung pada perederan darah sebagai inputan masukan data analog untuk di proses lebih lanjut oleh Raspberry.

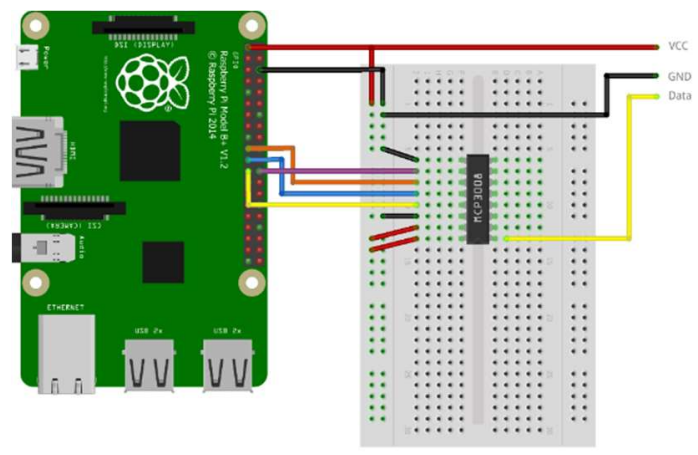

Gambar 8.Rangkaian Rancangan Alat

\section{ANALISI DAN PERANCANGAN}

\section{A. Perancangan Alat}

Dalam perancangan alat perangkat keras memerlukan beberapa perangkat atau modul yang diperlukan dalam pengerjaan. Di bawah ini beberapa gambar yang menunjukkan perangkat yang akan di gunakan.

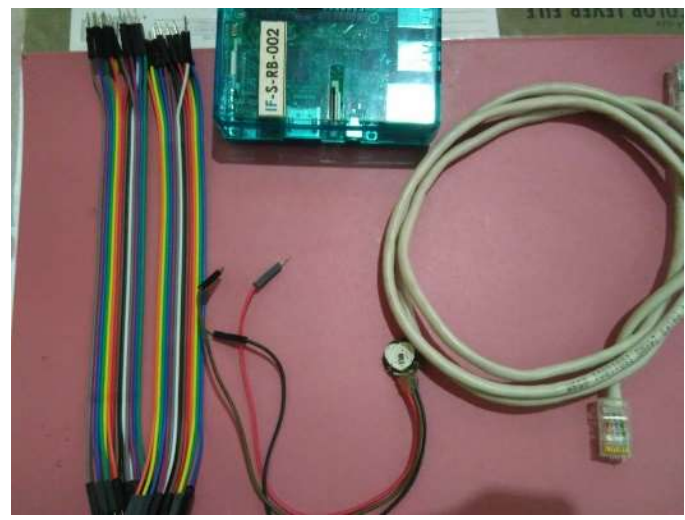

Gambar 9. Alat yang di perlukan

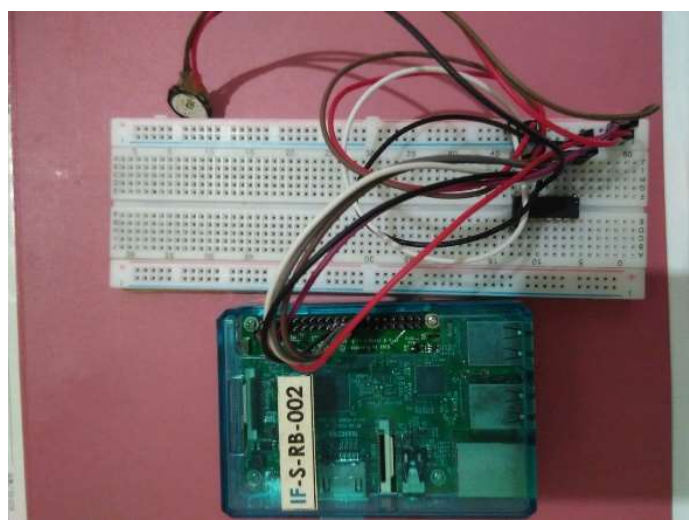

Gambar 10.Hasil setelah di rangkai

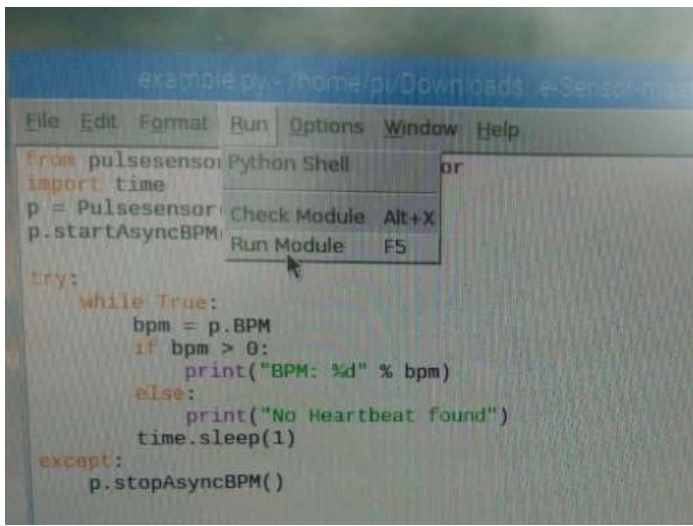

Gambar 11.Soruce yang digunakan untuk menjalankan keseluruhan modul

\section{B. Instalisasi Sistem Operasi}

Raspberry Pi tidak dilengkapi dengan memori untuk menyimpan sistem operasi, untuk itu membutuhkan sebuah SD-card untuk menginsatal sistem operasi Raspian OS. 


\section{Instalisasi MCP3008}

Dalam ADC tersebut diperlukan library untuk inisialisasi sebuah Modul untuk mendefinisikan jenis objek yang memungkinkan transaksi SPI pada host yang menjalankan kernel Linux. Kernel host harus memiliki dukungan SPI dan dukungan antarmuka perangkat SPI. Berikut ini adalah tahapan untuk menginstal OS Raspbian:

1) Pastikan file Raspbian.zip sudah ada di komputer yang digunakan untuk menginstall OS.

2) Ekstrak file Raspbian.zip sehingga didapatkan file Raspbian.img.

3) Hubungkan sdcard dengan komputer

4) Jalankan program win_32_disk_imager.exe dan klik tanda folder dan piih Raspbian.img.

5) Kemudian pilih device tujuan yang akan ditulis OS Rapbian.

6) Klik menu write, dan tunggu beberapa saat.

\section{Pengujian}

Berapa metode pengukuran detak jantung dengan Manual, Apps Icare dan Indikator Alat, dimana sampel acak yang dilakukan kepada perempuan dan laki-laki memiliki perbandingan error $0-3 \%$. Dalam setiap penghitungan memiliki ketentuan dalam pengambilan nilai seperti pada Manual terhitung dalan penghitungan selama 30 Detik di kali 4 dan menghasilkan nilai penghitungan Manual, Apps ICare penghitungan menggunakan salah satu apps yang terinstal kemudian menghitung dengan meletakkan jari telunjuk menutup kamera HandPhone selama 1 minutes. Dengan Alat yang di rancang pengambilan data detak jantung penghitungan selama 15 Detik dan hasil terakhir menjadi hasil detak jantung terakhir atau pada keluaran nilai yang sama secara looping.

Di bawah ini merupakan table perbandingan dari beberapa penggunaan ke 3 metode yang digunakan.

TABEL III

TABLE PERBANDINGAN METODE

\begin{tabular}{|c|c|c|c|c|c|}
\hline \multirow{2}{*}{ SAMPLE } & \multicolumn{3}{|c|}{ PENGHITUNGAN DETAK JANTUNG } & \multicolumn{2}{c|}{ SELISIH PERBEDAAN } \\
\cline { 2 - 7 } & SECARA MANUAL & APPS I CARE & INDIKATOR ALAT & JUMLAH & PRESENTASE \\
\hline PR/ 22 & 74 & 74 & 75 & 1 & 1,351351351 \\
\hline PR/21 & 64 & 65 & 65 & 1 & 1,5625 \\
\hline PR/21 & 70 & 70 & 71 & 1 & 1,428571429 \\
\hline PR/21 & 56 & 56 & 56 & 0 & 0 \\
\hline LK/23 & 80 & 80 & 80 & 0 & 0 \\
\hline LK/22 & 65 & 65 & 65 & 0 & 0 \\
\hline PR/21 & 64 & 64 & 65 & 1 & 1,5625 \\
\hline LK/22 & 77 & 77 & 80 & 3 & 3,896103896 \\
\hline & & & & & \\
\hline
\end{tabular}

$$
\text { error }=\frac{\text { selisih perhitungan }}{\text { jumlah perhitungan manual }} \times 100 \%
$$

Pengujian bertujun mengetahui kondisi perbandingan dari alat yang di buat dengan kondisi nyata. Dalam pengujian ini memiliki 3 perbandingan perhitungan. Penghitungan secara manual, yaitu perhitungan detak jantung arteri radalis yang berada pada pergelangan tangan. Dilakukan selama 1 menit karena satuan yang dilakuakan berupa Bite Per Minutes (BPM). Pengujian dengan Apps Icare mendukung agar penghitungan dapat menghasilkan nilai yang valid. Penghitungan melalui alat yang dirancang, yaitu mengetahui nilai pengukuran dalam setiap perhitungan dengan sensor pulse.

\section{KESIMPULAN DAN SARAN}

\section{A. Kesimpulan}

Dari hasil pengujian menggunakan pulse sensor berbasis Raspberry pi 3 sebagai mikrokontroler. Mulai dari analisis sistem, perancangan dan pengujian, dapat diambil kesimpulan antara lain sebagai berikut.

1) Perangkat merespon dan memberikan hasil pengukuran dengan melakukan 10-20 kali percobaan pengujian.

2) Modul dari source dapat di jalankan.

3) Kinerja Pulse Sensor memiliki tingkat sensitivitas dan pembacaan yang sedikit lambat.

\section{B. Saran}

1) Penambahan sensor lain, seperti misalnya mengenai informasi suhu tubuh lainnya.

2) Hasil dari nilai sensor dapat tersimpan ke Database xampp.

3) Menghubungkan ke Database yang berguna menampilkan grafik atau visualisasi dalam bentuk lainnya.

\section{DAFTAR PUSTAKA}

[1] Mulyono, Iwan Adi, 2002 "Perencanaan Dan Pembuatan Pendeteksi Alat Detak Jantung Dan Suhu Tubuh Berbasis Komputer" Skripsi, Universitas Katolik Soegijapranata Semarang.

[2] Rahadian,Helmy, Arifin,Zaenal. (2016). "Pemerosesan Data Pilse Sensor Amped Pada Rancangan Sistem Informasi Dokter Dan Pasien”. Semarang: Skripsi, Universitas Dian Nuswantoro Semarang.

[3] Harahab, Ahmad Nawawi, Bisman Perangin-angin, M.Eng.Sc.2013. Sistem Pengukuran Detak Jantung Manusia Menggunakan Media Online dengan Jaringan Wi-Fi Berbasis PC. FMIPA Universitas Sumatera Utara, Medan.

[4] Deming, W.E., 1986, Out of Crisis, MIT Center for Advanced Engineering Study, Cambridge, MA

[5] M. Wegmuller, J. P. von der Weid, P. Oberson, \& N. Gisin, "High resolution fiber distributed measurements with coherent OFDR," Prosiding ECOC'00, 2000, paper 11.3.4, p. 109.

[6] Hamdan Heruryanto1, Wira Bahari Nurdin, Bidayatul Armynah (2014)." Sistem Pengukuran Denyut Jantung Berbasis Mikrokontroler Atmega8535". Makassar.

[7] Heruryanto, Hamdan. (2014). "Sistem Pengukuran Detak Jantung Berbasis Mikrokontroller Amage8535". Makassar: Tugas Akhir, Universitas Hasanuddin.

[8] Erliyanto, Machriz, dkk. 2008. Perancangan Perangkat Monitoring Denyut Jantung (Heart-BeatMonitoring) dengan Visualisasi Lcd Grafik Berbasis Atmel At89C. Jurusan Teknik Elektro - Institut TeknologiTelkom. Bandung.

[9] Kurniawan, D. E., \& Fani, S. (2017). Perancangan Sistem Kamera Pengawas Berbasis Perangkat Bergerak Menggunakan Raspberry Pi. Jurnal Ilmiah Teknologi Informasi Terapan, 3(2).

[10] Kurniawan, D. E., \& Surur, M. N. (2017). Sistem Pengaman Sepeda Motor Berbasis Perangkat Bergerak dengan Notifikasi dan Kendali Mesin. Jurnal Sistem Informasi, 9(1).

[11] Prapanca, S.T., M.Kom., Aditya. (2016). Raspberry http://if.unesa.ac.id/blog/aditya/2015/11/18/198/http://www.ahlinyap enyakitjantung.web.id/angka-kematian-penyakit-jantung-diindonesia/ 